\title{
Sorption Efficiency of a New Sorbent towards Cadmium(II): Methylphosphonic Acid Grafted Polystyrene Resin
}

\author{
Nacer Ferrah, ${ }^{1}$ Omar Abderrahim, ${ }^{1}$ Mohamed Amine Didi, ${ }^{1}$ and Didier Villemin ${ }^{2}$ \\ ${ }^{1}$ Laboratory of Separation and Purification Technology, Department of Chemistry, Tlemcen University, Box 119, Tlemcen, Algeria \\ ${ }^{2}$ Laboratoire de Chimie Moléculaire et Thioorganique, UMR CNRS 6507, INC3M, FR 3038, ENSICAEN and Université de Caen, \\ 14050 Caen, France
}

Correspondence should be addressed to Omar Abderrahim; abderrahimomar@yahoo.fr

Received 8 June 2012; Accepted 20 August 2012

Academic Editor: Julie Hardouin

Copyright (C) 2013 Nacer Ferrah et al. This is an open access article distributed under the Creative Commons Attribution License, which permits unrestricted use, distribution, and reproduction in any medium, provided the original work is properly cited.

\begin{abstract}
A new chelating polymeric sorbent has been developed using polystyrene resin grafted with phosphonic acid. After characterization by FTIR and elementary analysis, the new resin has been investigated in liquid-solid extraction of cadmium(II). The results indicated that phosphonic resin could adsorb Cd(II) ion effectively from aqueous solution. The adsorption was strongly dependent on the $\mathrm{pH}$ of the medium and the optimum $\mathrm{pH}$ value level for better sorption was between 3.2 and 5.2. The influence of other analytical parameters including contact time, amount of resin, metal ion concentration, and the presence of some electrolytes was investigated. The maximum uptake capacity of Cd(II) ions was $37,9 \mathrm{mg} \cdot \mathrm{g}^{-1}$ grafted resin at ambient temperature, at an initial $\mathrm{pH}$ value of 5.0 . The overall adsorption process was best described by pseudo second-order kinetic. When Freundlich and Langmuir isotherms were tested, the latter had a better fit with the experimental data. Furthermore, more than $92 \%$ of Cd(II) could be eluted by using $1.0 \mathrm{~mol} \cdot \mathrm{L}^{-1} \mathrm{HCl}$ in one cycle.
\end{abstract}

\section{Introduction}

Some heavy metals like $\mathrm{Cd}, \mathrm{Hg}, \mathrm{As}, \mathrm{Pb}$, and so forth have no biological function and are detrimental to the organisms even at a very low concentration [1]. They originate from natural sources such as rocks, metalliferous minerals, and anthropogenic inputs from agriculture, metallurgy, energy production, microelectronics, mining, sewage sludge, and waste disposal $[2,3]$. A concentration higher than the prescribed limit may lead to the formation of nonspecific complex compounds in the cell, which leads to toxic effects. The major sources of cadmium release into the environment are electroplating, smelting, plastics, batteries, paint pigments, and mining and refining processes [4].

In this industrialized era, the presence of cadmium ions in aqueous water ways has become a serious environmental problem, and many methods such as ion exchange, surface complexation, diffusion through the solid, reverse osmosis, membrane separation, chemical oxidation or reduction, coprecipitation, and control of sample-specific surface area have been employed to remove it from wastewater [5-8]. It reveals that surface complexation is the most important mechanism with possibly ion exchange and solid diffusion also contributing to the overall sorption process [9]. The use of solid phase extraction has been proved to be more advantageous in the view of their total insolubility in aqueous phase, low rate of physical degradation, high sorption capacity for metal ions, low organic solvent inventory, and good flexibility in working conditions [9].

In the present work, we described the synthesis and characterization of polystyrene resin grafted with phosphonic acid. This resin was applied as a new sorption material for cadmium(II) extraction in batch process. The effects of analytical parameters, adsorption kinetic, isotherm studies, and desorption process were investigated.

\section{Experimental}

2.1. Instrumentation. Infrared spectra were recorded on a Perkin-Elmer ATR spectrometer. A Bruker Advance 400 spectrometer was used for ${ }^{13} \mathrm{C}$ and ${ }^{31} \mathrm{P}$ MAS NMR analysis. 
Elemental analyses were carried out on a Thermoquest CHP analyzer. Visible spectra were measured using Perkin-ElmerLambda 800 UV-Vis spectrophotometer. pH measurements were taken on a potentiometer Consort C831.

2.2. Reagents. Chloromethyl styrene-divinylbenzene copolymer (S-3\% DVB) was precursor of Amberlite resin, gifted by Rohm and Haas Company. Triethylphosphite, hydrobromic acid, acetic acid, oxalic acid, sodium acetate, sodium sulphate, sodium hydroxide (80\%), dichloromethane, sulphuric acid 95-97\%, acetone, and 4-(2-pyridylazo)resorcinol (PAR) were provided from Fluka. Cadmium sulphate (99\%), sodium nitrate, sodium acetate, ethylenediaminetetraacetic acid (EDTA), ammonium carbonate, and sodium chloride were obtained from Merck. Hydrochloride acid (36\%) and nitric acid (65\%) were purchased from Reidel-de-Haen.

Stock solution $\left(1.0 \mathrm{~mol} \cdot \mathrm{L}^{-1}\right)$ of cadmium(II) was prepared by dissolving her sulphate salt in distilled water. Solutions of lower concentrations were prepared by the dilution of stock solution.

\subsection{Synthesis of Polystyrene Resin Anchored with Phosphonic} Acid. The sorbent, phosphonic acid grafted polystyrene resin beads, was synthesized using the Arbuzov reaction [10-13] (Figure 1). In the first step, after washing the Merrifield resin beads with acetone and dried under vacuum, Merrifield resin $3 \%$ (20.34 g) was reacted with $35 \mathrm{~mL}$ of triethylphosphite (excess). The reaction mixture was refluxed for 4 hours (hrs). The phosphonate grafted polystyrene resin beads obtained were purified from the excess of reactants by washing repeatedly with water and acetone. The resin beads were dried under vacuum (14.26 g). In the second step, a bromide hydrogen acid $(33 \mathrm{~mL})$ was added on the phosphonate grafted polystyrene resin beads ( $10.00 \mathrm{~g}$ ) and vigorously shaken on a vibrating table under reflux for $3 \mathrm{hrs}$. In order to remove unreacted reagents, the resulting resin beads were filtered, washed repeatedly with distilled water and dichloromethane, and dried in vacuum $(8.62 \mathrm{~g})$.

2.4. Characterization Studies. The structure and purity of the final complexing agent were identified and characterized by MAS NMR of ${ }^{31} \mathrm{P}$ and ${ }^{13} \mathrm{C}$ spectroscopy, FTIR measurement, and elemental microanalysis. The MAS NMR spectra showed the expected signals due to the polystyrene skeleton and phosphonic units as matched to the proposed structure (Figure 1).

${ }^{31} \mathrm{P}$ MAS NMR is $17.8 \mathrm{ppm},{ }^{13} \mathrm{C}$ MAS is $36.4 \mathrm{ppm}$ $\left(\mathrm{CH}_{2}-\mathrm{P}\right), 127.75,130.1,137.1$, and $138.5(\mathrm{CH}-\mathrm{CH}) \mathrm{ppm}$. The presence of phosphonic acid was confirmed by the appearance of absorption at $3000-2850 \mathrm{~cm}^{-1}(\mathrm{OH}), 1124 \mathrm{~cm}^{-1}$ $(\mathrm{P}=\mathrm{O}), 1037 \mathrm{~cm}^{-1}\left(v_{\text {as }} \mathrm{P}-\mathrm{OH}\right)$, and $941 \mathrm{~cm}^{-1}\left(v_{\mathrm{s}} \mathrm{P}-\mathrm{OH}\right)$ and by the disappearance of P-OEt band at $1023 \mathrm{~cm}^{-1}$ [14]. The experimental CHP analysis data (\%) of phosphonic acid grafted polystyrene resin is $\mathrm{C}, 85.31 ; \mathrm{H}, 9.34 ; \mathrm{P}, 2.35$.

2.5. Adsorption Technique. Batch technique was applied to investigate the different parametric effects on the sorption process, where a certain weight $0.030 \mathrm{~g}(\mathrm{~m})$ of the grafted resin was mixed with a certain volume $5 \mathrm{~mL}(V)$ of $\mathrm{Cd}$ (II) aqueous solutions and equilibrated by shaking in a shaker with speed 250 round per minute (rpm) at room temperature. The ratio of $m / V\left(6.0 \mathrm{~g} \cdot \mathrm{L}^{-1}\right)$ was kept constant for all the experiments. The solutions were separated after a certain time $(t)$ and the concentrations of $\mathrm{Cd}(\mathrm{II})$ in the aqueous phase were determined, before and after extraction spectrophotometrically with PAR at $\mathrm{pH} 5.5$ [15]. The absorbance of PAR-cadmium(II) complex was measured at $520 \mathrm{~nm}$. The extraction yield (\%) was determined using the following equation:

$$
\text { Extraction yield }(\%)=\left(\frac{C_{0}-C_{e}}{C_{0}}\right) 100 \%,
$$

where $C_{0}$ and $C_{e}$ denote the initial and equilibrium concentrations of $\mathrm{Cd}(\mathrm{II})$ in the aqueous phase $\left(\mathrm{mol} \cdot \mathrm{L}^{-1}\right)$.

2.6. Kinetic and Sorption Isotherms. In order to quantify the extent of uptake in adsorption kinetics three simple kinetic models were tested [16].

(1) Lagergren's pseudo first-order rate equation expressed as follows:

$$
\log \left(q_{e}-q_{t}\right)=\log q_{e}-\frac{k_{1}}{2.303} t
$$

where $k_{1}\left(\mathrm{~min}^{-1}\right)$ is the equilibrium rate constant of the pseudo first-order adsorption, $q_{t}$ and $q_{e}$ are the amount of $\mathrm{Cd}(\mathrm{II})$ adsorbed $\left(\mathrm{mg} \mathrm{g}^{-1}\right)$ at time $t$ and equilibrium time (180 min), respectively. The values of $k_{1}$ and $q_{e}$ can be obtained from the intercept and slope of the plot of $\left(\log \left(q_{e}-q_{t}\right)\right)$ versus $(t / 2.303)$.

(2) A pseudo second-order adsorption kinetic rate equation is

$$
\frac{t}{q_{t}}=\frac{1}{k_{2} q_{e}^{2}}+\frac{t}{q_{e}}
$$

where $k_{2}\left(\mathrm{~g} \cdot \mathrm{mg}^{-1} \cdot \mathrm{min}^{-1}\right)$ is the rate constant of the pseudo second-order adsorption. The values of $k_{2}$ and $q_{e}$ were obtained from the intercept and slope of the plot of $\left(t / q_{t}\right)$ versus $t$.

(3) A second-order adsorption kinetic rate equation is

$$
\frac{1}{q_{e}-q_{t}}=\frac{1}{q_{e}}+k_{3} t
$$

where $k_{3}\left(\mathrm{~g} \cdot \mathrm{mg}^{-1} \cdot \mathrm{min}^{-1}\right)$ is the rate constant of the second-order adsorption. The values of $k_{3}$ and $q_{e}$ can be obtained from the intercept and slope of the plot of $\left(1 /\left(q_{e}-q_{t}\right)\right)$ versus $t$.

Sorption isotherms for $\mathrm{Cd}(\mathrm{II})$ were determined over the concentration range of $10^{-3}$ to $10^{-2} \mathrm{~mol} \cdot \mathrm{L}^{-1}$. The amount of ions sorbed by phosphonic resin, $q_{t}\left(\mathrm{mg}^{-g^{-1}}\right)$ was calculated by the following relationship:

$$
q_{t}\left(\frac{\mathrm{mg}}{\mathrm{g}}\right)=\left(C_{0}-C_{t}\right) \cdot V \cdot \frac{M}{m},
$$




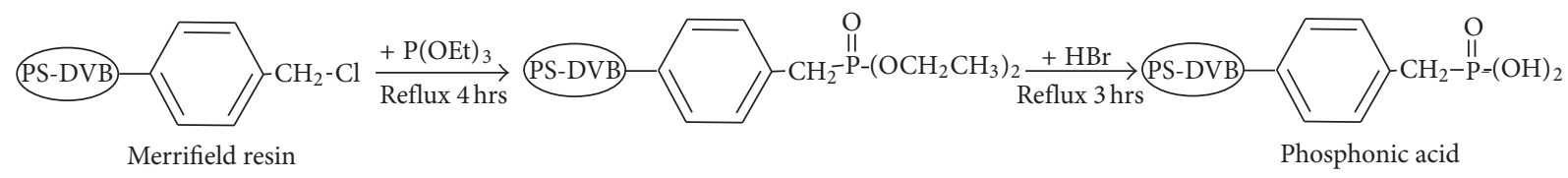

FIGURE 1: Scheme for synthesis of methylene phosphonic acid grafted polystyrene resin beads.

where $C_{t}$ is the final concentrations at certain time $t$ of the ions in the liquid phase $\left(\mathrm{mol} \cdot \mathrm{L}^{-1}\right), V$ is the volume of the aqueous phase $(5 \mathrm{~mL}), m$ is the weight of grafted resin $(0.030 \mathrm{~g})$, and $M\left(112.411 \mathrm{~g} \cdot \mathrm{mol}^{-1}\right)$ is the atomic weight of cadmium.

\section{Results and Discussion}

3.1. Effect of $\mathrm{pH}$. Changes in the $\mathrm{pH}$ of the medium are one of the most important factors affecting the concentration and metal recovery procedure, which is related to the formation of soluble metal complexes and subsequently their stabilities in aqueous solutions. It is well known that surface charge of adsorbent can be modified by changing the $\mathrm{pH}$ of the solution and the chemical species in the solution depends on this parameter [17]. According to the chemical equilibrium diagram for cadmium in aqueous solution obtained by the MEDUSA program, the species $\mathrm{Cd}(\mathrm{OH})_{2}$ precipitates at $\mathrm{pH}$ higher than 8 and the concentration of $\mathrm{Cd}^{2+}$ ions in solution decreases. (Program MEDUSA, Make Equilibrium Diagrams Using Sophisticated Algorithms. http://home.telfort.nl/cheaqs/). Under the experimental conditions of the present paper, $\mathrm{Cd}^{2+}$ was the major species present in solution.

In order to optimize the $\mathrm{pH}$ for maximum removal, experiments were conducted in the $\mathrm{pH}$ range from 1.77 to 5.15 at ambient temperature, $4 \mathrm{hrs}$ equilibration time, and $1.0 \mathrm{mmol} \cdot \mathrm{L}^{-1}$ metal ion concentration. Figure 2 shows the influence of $\mathrm{pH}$ in sorption process of $\mathrm{Cd}(\mathrm{II})$ by modified resin. As can be seen from Figure 2 the sorption increases quickly with increasing $\mathrm{pH}$ values from 1.8 to 3.2. The progressive decrease in the retention of metal ions at low $\mathrm{pH}$ is due to [17] the following: (i) the competition of the hydrogen ion with the metal ions for binding to the phosphonic acid group $(\mathrm{P}-\mathrm{OH})$; (ii) the oxygen atoms $(\mathrm{P}=\mathrm{O})$ are more protonated, and hence, they are less available to coordinate with the cadmium; (iii) the competition between the excess of $\mathrm{H}^{+}$ions in the medium and positively charged cationic species present in solution; (iv) as $\mathrm{pH}$ is increased there is a decrease of positive surface charge, which results in the lower coulombic repulsion of the adsorbing metal ions. Consequently the number of moles of Cd(II) removal may decrease at low $\mathrm{pH}$ [18]. The observed reduction in the level of metal ion removal from solution by the sorbent indicates that the interaction between the $\mathrm{Cd}(\mathrm{II})$ ions and the sorbent is an ion exchange process.

The data reveals that the highest extraction yield value is recorded at the $\mathrm{pH}$ range 3.2-5.2. This is attributed to the presence of free lone pair of electrons on the oxygen of phosphoryl $(\mathrm{P}=\mathrm{O})$ group and deprotonated oxygen atoms,

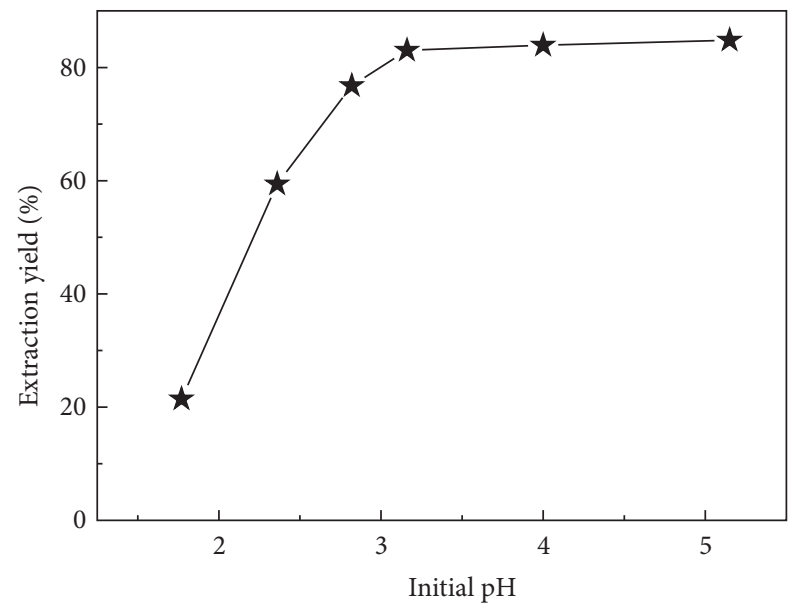

FIgURE 2: Effect of the initial $\mathrm{pH}$ of the aqueous solution on the retention of $\mathrm{Cd}(\mathrm{II})$ by the functionalized resin. $C_{0}=1.0 \mathrm{mmol} \cdot \mathrm{L}^{-1}$, $m=0.030 \mathrm{~g}, V=5 \mathrm{~mL}$, and contact time $=4 \mathrm{hrs}$.

which are suitable ligands for coordination with the cadmium ions $[19,20]$. This cation exchange process can be represented by the following general reaction [6]:

$$
\text { Resin-P-OH }+\mathrm{Cd}^{2+} \longrightarrow \text { Resin-P-O-Cd }{ }^{+}+\mathrm{H}^{+} .
$$

In order to make further approaching of the functional group of resin and $\mathrm{Cd}(\mathrm{II})$, the spectra of resin, before and after $\mathrm{Cd}(\mathrm{II})$ is sorbed, are compared. It is found that the characteristic sorption peak of the bond $\mathrm{P}=0\left(\right.$ at $\left.1124 \mathrm{~cm}^{-1}\right)$ disappears on the whole, which shows that the formation of the coordination bond between oxygen atom and $\mathrm{Cd}(\mathrm{II})$ weakens the stretch vibration and causes the peak to shift to the lower frequency. The characteristic sorption peak of $\mathrm{P}-\mathrm{OH}\left(941 \mathrm{~cm}^{-1}\right)$ is weakened and the new characteristic sorption peak of $\left(-\mathrm{PO}_{3}{ }^{2-}\right)$ is formed [21], which shows that $\mathrm{H}^{+}$and $\mathrm{Cd}^{2+}$ has been exchanged. All those changes result from the formation of a complex compound.

3.2. Effect of Contact Time. The rate of loading of Cd(II) onto the grafted polystyrene resin was determined for two concentrations of Cd(II) 0.5 and $1.0 \mathrm{mmol} \cdot \mathrm{L}^{-1}$, by shaking $5 \mathrm{~mL}$ of Cd(II) with $0.030 \mathrm{~g}$ of resin in an Erlenmayer flask at ambient temperature for $2,4,10,15,30,60,120,180$, and $200 \mathrm{~min}$. Figure 3 shows that the initial concentration of Cd(II) has an important effect on the rate of sorption. For all the sorption experiments, the amount of cadmium ions sorbed onto the grafted resin increased quickly with time and then slowly reached equilibrium after $180 \mathrm{~min}$. The equilibrium times in which the polymer attains 50\% saturation with Cd(II) (half 


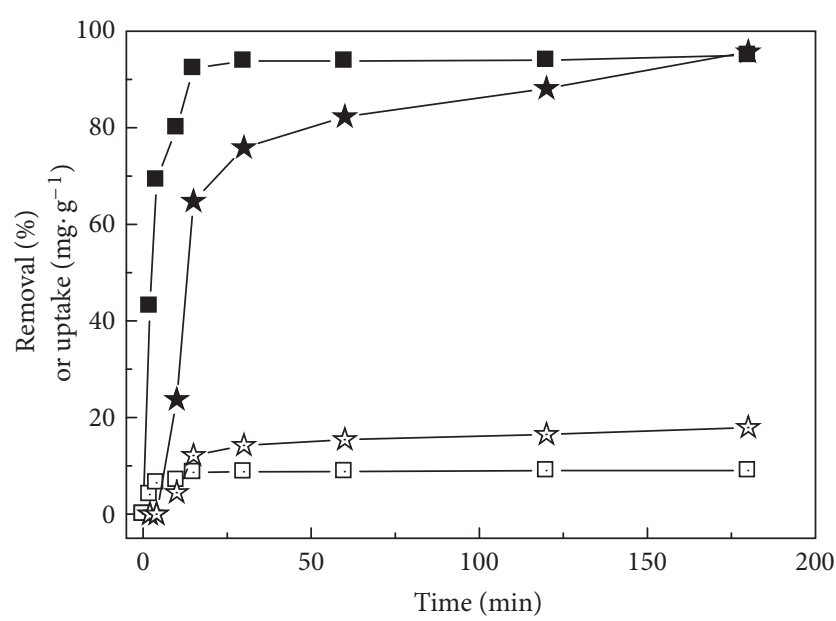

FIgURE 3: Effect of contact time on the sorption of Cd(II) on the functionalized resin from aqueous $\mathrm{Cd}(\mathrm{II})$ solutions at two different concentrations $\left(C_{0}\right.$ and $\left.C_{0}^{\prime}\right) ; C_{0}=0.5 \mathrm{mmol} \cdot \mathrm{L}^{-1}$ : a-percent $\mathrm{Cd}(\mathrm{II})$ removal, (\%), $\square$-uptake $(q), \mathrm{mg} \cdot \mathrm{g}^{-1} ; C_{0}^{\prime}=1.0 \mathrm{mmol} \cdot \mathrm{L}^{-1}: \star$-percent

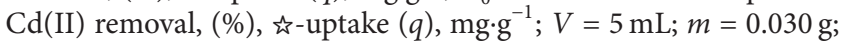
initial $\mathrm{pH}=5.0$.

time $t_{1 / 2}$ ) are $<2.4 \mathrm{~min}$ and $<13.0 \mathrm{~min}$ for initial Cd(II) concentration $=0.5 \mathrm{mmol} \cdot \mathrm{L}^{-1}$ and $1.0 \mathrm{mmol} \cdot \mathrm{L}^{-1}$, respectively. The amounts of cadmium metal ions sorbed at equilibrium $\left(q_{e}\right)$ at $[\mathrm{Cd}(\mathrm{II})]=0.5 \mathrm{mmol} \cdot \mathrm{L}^{-1}$ and $1.0 \mathrm{mmol} \cdot \mathrm{L}^{-1}$, respectively, are 9.02 and $17.93 \mathrm{mg} \cdot \mathrm{g}^{-1}$.

3.3. Rate of Kinetics Adsorption. In this study, batch sorption kinetics of $\mathrm{Cd}(\mathrm{II})$ ions at two different concentrations, $C_{0}=$ 0.5 and $C_{0}^{\prime}=1.0 \mathrm{mmol} \cdot \mathrm{L}^{-1}$, with the functionalized polymer have been studied. The different values of constants from the slopes and intercepts of linear plots of (2) (figure not shown), (3) (shown in Figure 4), and (4) (figure not showed) are summarized in Table 1. As seen from Table 1, the obtained correlation coefficient for the pseudo second-order model ( $>0.99$ ) was better than those of the first-order and secondorder models for the adsorption of $\mathrm{Cd}(\mathrm{II})$ at the two considered concentrations, suggesting that the pseudo secondorder model was more suitable to describe the adsorption kinetics of phosphonic acid grafted on polystyrene resin for Cd(II), especially at the lower concentration $\left(0.5 \mathrm{mmol} \cdot \mathrm{L}^{-1}\right)$. This suggests that the rate limiting step may be chemical sorption or chemisorption involving valency forces through sharing or exchange of electrons between sorbent (containing $\mathrm{O}$ atoms) and sorbate [16]. Similar results have been observed in the adsorption of Cd(II) by lignocellulosic sorbent [22] and onto kraft and organosolv lignins [23]. The values of the second-order rate constants $\left(k_{2}\right)$ were found to decrease from 1.6442 to $0.00262 \mathrm{~g} \cdot \mathrm{mg}^{-1} \cdot \mathrm{min}^{-1}$ as the initial concentration increased from 0.5 to $1.0 \mathrm{mmol} \cdot \mathrm{L}^{-1}$, showing the process to be highly concentration dependent, which is consistent with studies reported [24].

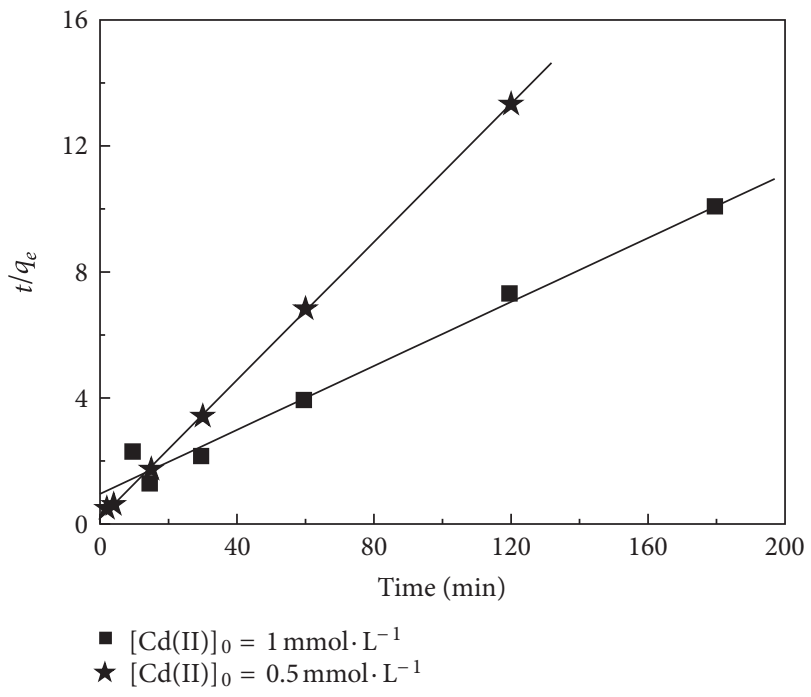

Figure 4: Plots for the adsorption of Cd(II), $m=0.030 \mathrm{~g}, V=5 \mathrm{~mL}$, and initial $\mathrm{pH}=5.0$.

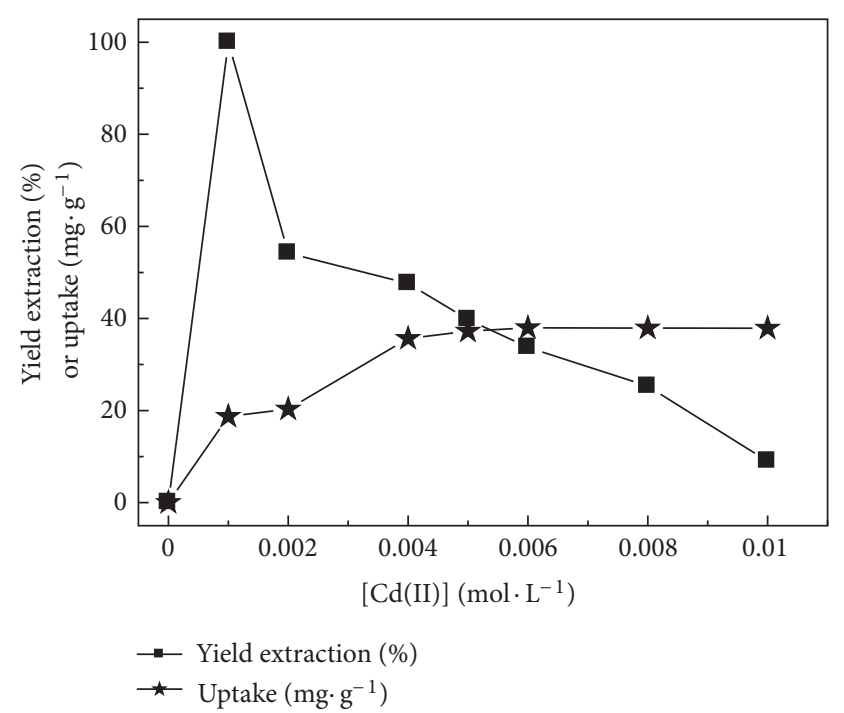

FIGURE 5: Effect of the initial concentration of Cd(II) on the uptake and the extraction yield. $m=0.030 \mathrm{~g}, V=5 \mathrm{~mL}$, equilibrium time $=$ $180 \mathrm{~min}$, and initial $\mathrm{pH}=5.0$.

3.4. Sorption Capacity. The retention capacity of functionalized resin was determined by equilibrating $0.030 \mathrm{~g}$ of the resin with $5 \mathrm{~mL}$ of cadmium(II) ion solutions at different concentrations $\left(0.1 .10^{-2}-1.0 .10^{-2} \mathrm{~mol} \cdot \mathrm{L}^{-1}\right)$, under optimum $\mathrm{pH}$. The experimental capacity obtained is $37.9 \mathrm{mg} \cdot \mathrm{g}^{-1}$ of polymer (Figure 5). At similar conditions, this sorbent possesses very high extraction ability towards $\mathrm{Eu}(\mathrm{III})$ and $\mathrm{UO}_{2}{ }^{2+}$ cations metals; the extraction capacities are 122.5 and $152.2 \mathrm{mg} \mathrm{g}^{-1}$, respectively $[25,26]$. This result is attributed to that phosphonic acid derivatives are more selective towards lanthanides elements [27]. 
TABLE 1: Models rate constants for Cd(II) sorption kinetics by the functionalized resin.

\begin{tabular}{lccc}
\hline Models & Parameters & {$[\mathrm{Cd}(\mathrm{II})]_{0}=0.5 \mathrm{mmol} \cdot \mathrm{L}^{-1}$} & {$[\mathrm{Cd}(\mathrm{II})]_{0}=1.0 \mathrm{mmol} \cdot \mathrm{L}^{-1}$} \\
\hline \multirow{3}{*}{ First-order rate } & $q_{\text {cal. }}\left(\mathrm{mg}^{-1}\right)$ & 2.20 & 12.43 \\
& $q_{\text {exp. }}\left({\left.\mathrm{mg} \cdot \mathrm{g}^{-1}\right)}\right.$ & 9.02 & 17.93 \\
& $k_{1}\left(\mathrm{~min}^{-1}\right)$ & 0.050 & 0.020 \\
& $r$ & 0.800 & 0.880 \\
Pseudo second-order rate & $q_{\text {cal. }}\left(\mathrm{mg} \cdot \mathrm{g}^{-1}\right)$ & 9.09 & 20.0 \\
& $q_{\text {exp. }}\left(\mathrm{mg}^{-1}\right)$ & 9.02 & 17.93 \\
& $k_{2}\left(\mathrm{~g} \cdot \mathrm{mg}^{-1} \cdot \mathrm{min}^{-1}\right)$ & 1.6442 & 0.00262 \\
Second-order rate & $r$ & 0.999 & 0.991 \\
& $q_{\text {cal. }}\left(\mathrm{mg}^{-1}\right)$ & 0.67 & 14.37 \\
& $q_{\text {exp. }}\left(\mathrm{mg}^{-1}\right)$ & 9.02 & 17.93 \\
& $k_{3}\left(\mathrm{~g} \cdot \mathrm{mg}^{-1} \cdot \mathrm{min}^{-1}\right)$ & 0.8052 & 0.05599 \\
\hline
\end{tabular}

3.5. Adsorption Isotherm. The adsorbed amounts of Cd(II) on resin have been determined as a function of the metal concentration in the supernatant at the equilibrium state and ambient temperature. The Langmuir treatment (7) is based on the assumption that [28] (i) maximum adsorption corresponds to saturated monolayer of adsorbate molecules on the adsorbent surface, (ii) the energy of adsorption is constant, and (iii) there is no transmigration of adsorbate in the plane of the surface. One has

$$
\frac{C_{e}}{q_{e}}=\frac{C_{e}}{q_{m}}+\frac{1}{q_{m} K_{L}},
$$

where $q_{m}$ and $K_{L}$ are Langmuir constants related to adsorption capacity and energy of adsorption, respectively. The linear plot of $C_{e} / q_{e}$ versus $C_{e}$ shows that adsorption obeys Langmuir adsorption model (Figure 6). The correlation coefficient for the linear regression fits of the Langmuir plot was found to be 0.995. $q_{m}$ and $K_{L}$ determined from the Langmuir plot were found to be $38.2 \mathrm{mg} \cdot \mathrm{g}^{-1}$ and 0,0441 $\mathrm{L} \cdot \mathrm{mol}^{-1}$, respectively. We note that the capacity of sorption deducted after Langmuir model application is similar to this calculated experimentally $\left(37.9 \mathrm{mg} \cdot \mathrm{g}^{-1}\right)$.

The essential characteristics of Langmuir isotherm can be expressed in terms of a dimensionless constant, separation factor or equilibrium parameter, $R_{L}$ which is defined by

$$
R_{L}=\frac{1}{1+K_{L} C_{0}} .
$$

The value of $R_{L}$ indicates the type of the isotherm to be either unfavorable $\left(R_{L}>1\right)$, linear $\left(R_{L}=1\right)$, favorable $(0<$ $\left.R_{L}<1\right)$, or irreversible $\left(R_{L}=0\right)$. As shown in Table 2 , the values of $R_{L}$ are ranged from 0.9999 to 0.9995 in the initial $\mathrm{Cd}(\mathrm{II})$ ions concentrations $0.01-0.001 \mathrm{~mol} \cdot \mathrm{L}^{-1}$. These values indicated that the adsorption process is favorable [29, 30].

The Freundlich equation was also applied to the adsorption. The Freundlich equation is basically empirical but is often useful as a means of data description. It generally agrees quite well compared to Langmuir equation and experimental

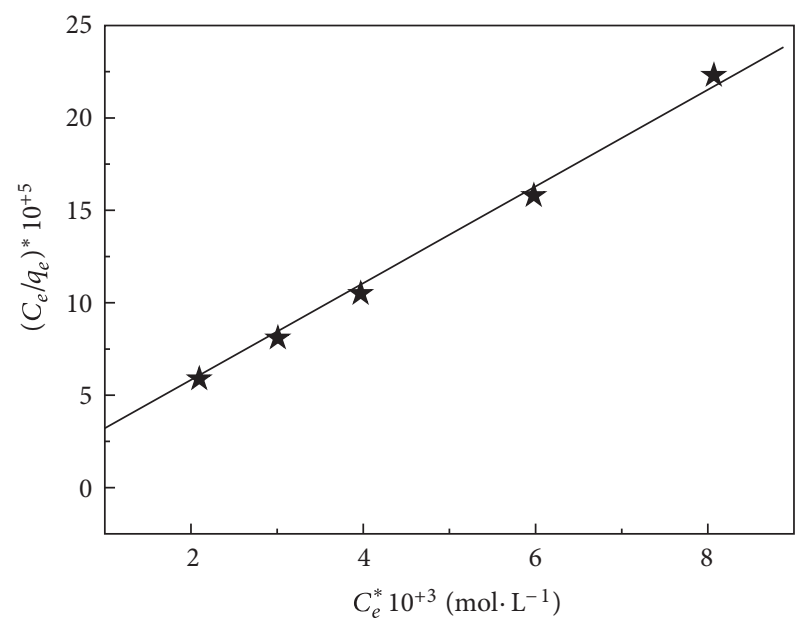

FIGURE 6: Langmuir plot for the adsorption of Cd(II), $m=0.030 \mathrm{~g}$, $V=5 \mathrm{~mL}$, initial $\mathrm{pH}=5.0$, and equilibrium time $=180 \mathrm{~min}$.

data over a moderate range of adsorbate concentrations [28]. The linearized Freundlich isotherm is represented by

$$
\log q_{e}=\log K_{F}+\frac{1}{n} \log C_{e}
$$

A plot of $\log \left(q_{e}\right)$ versus $\log C_{e}$ (figure not shown) is linear at only low concentrations of $\mathrm{Cd}$ (II) and the constants $K_{F}$ and $n$ were found to be $154.74 \mathrm{mg} \cdot \mathrm{g}^{-1}$ and 0.266 , respectively. The correlation coefficient for the linear regression fits of the Freundlich plot was found to be 0.830 .

3.6. Diffusion Study. The adsorption of cadmium(II) on the grafted resin from cadmium sulphate solutions at two different initial metal concentrations was studied as a function of time at ambient temperature. The adsorption onto ion exchange resin must be considered as a liquid-solid phase reaction which includes several steps [31]: (i) The diffusion of ions from the solution to the resin surface, (ii) the diffusion of ions within the solid resin, and (iii) the chemical reaction between ions and functional groups of the resin. 
TABLE 2: Equilibrium parameter, $R_{L}$.

\begin{tabular}{lccccccc}
\hline $\mathrm{C}_{0}, \mathrm{~mol} \cdot \mathrm{L}^{-1}$ & 0.001 & 0.002 & 0.004 & 0.005 & 0.006 & 0.008 & 0.01 \\
\hline$R_{L}$ & 0.99995 & 0.99991 & 0.99982 & 0.99977 & 0.99973 & 0.99964 & 0.99955 \\
\hline
\end{tabular}

TABLE 3: The regression equations $(y)$, regression coefficients $(r)$, and diffusion coefficients $\left(D_{r}\right)$.

\begin{tabular}{lcccc}
\hline$[\mathrm{Cd}(\mathrm{II})], \mathrm{mmol} \cdot \mathrm{L}^{-1}$ & & Eq. (10) & Eq. (11) & Eq. (13) \\
\hline \multirow{4}{*}{0.5} & $Y$ & $0.106 t$ & $0.098 t$ & $0.024 t$ \\
& $r$ & 0.925 & 0.932 & 0.900 \\
& $D_{r}, 10^{-5}, \mathrm{~cm}^{2} \cdot \mathrm{min}^{-1}$ & - & 2.485 & - \\
\hline \multirow{4}{*}{1.0} & $Y$ & $0.062 t$ & $0.040 t$ & $0.015 t$ \\
& $r$ & 0.941 & 0.951 & 0.945 \\
& $D_{r}, 10^{-5}, \mathrm{~cm}^{2} \cdot \mathrm{min}^{-1}$ & - & 1.014 & - \\
\hline
\end{tabular}

The adsorption of the metal is governed by the slowest of these processes. The kinetic models and the rate equations for the above three cases have been established. The exchange of ions can be described by the Nernst-Planck equations which apply to counter diffusion of two species in an almost homogeneous media $[17,31]$.

If the liquid film diffusion controls the rate of exchange, the following relation can be used:

$$
-\ln (1-F)=k t \text {. }
$$

If the cases of the diffusion of ions in the resin phase controlling process, the equation used is:

$$
-\ln \left(1-F^{2}\right)=k t
$$

After testing both mathematical models proposed for homogeneous diffusion in the adsorption of $\mathrm{Cd}$ (II) onto the resin, this is best fitted when the metal uptake is the particle diffusion controlled and at time contact $\leq 30 \mathrm{~min}$ (Figure 7 ). Thus, the values of the adsorption rate constant, regression equations, and regression coefficients of the diffusion of $\mathrm{Cd}(\mathrm{II})$ in the resin phase calculated from the slope of the straight lines (Figure 7) are summarized in Table 3.

In both (10) and (11), $k$ is the kinetic coefficient or rate constant. $k$ is defined by expression (12):

$$
k=\frac{D_{r} \pi^{2}}{r_{0}^{2}}
$$

where $D_{r}$ is the diffusion coefficient in the resin phase and $r_{0}$ is the average radius of resin particle. The values of the diffusion coefficient in the resin phase calculated from (12) are also given in Table 3.

When the adsorption of metal ion involves mass transfer accompanied by chemical reaction the process can be explained by the moving boundary model [32]. This model assumes a sharp boundary that separates a completely reacted shell from an unreacted core and that advances from the surface toward the center of the solid with the progression of adsorption. In this case, the rate equation is given by

$$
3-3(1-F)^{2 / 3}-2 F=k t .
$$

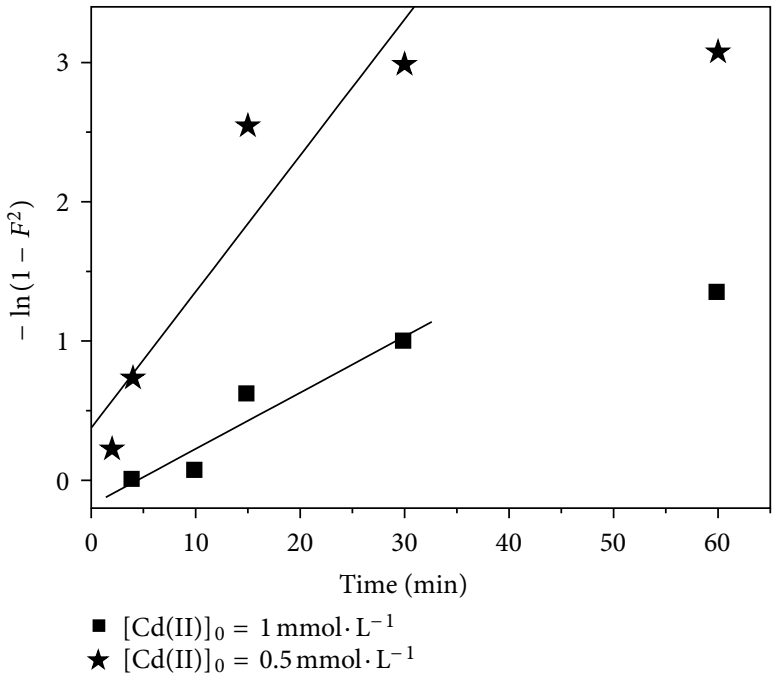

Figure 7: Plot of (11) for Cd(II) adsorption on grafted resin, $m=$ $0.030 \mathrm{~g}, V=5 \mathrm{~mL}$, and initial $\mathrm{pH}=5.0$.

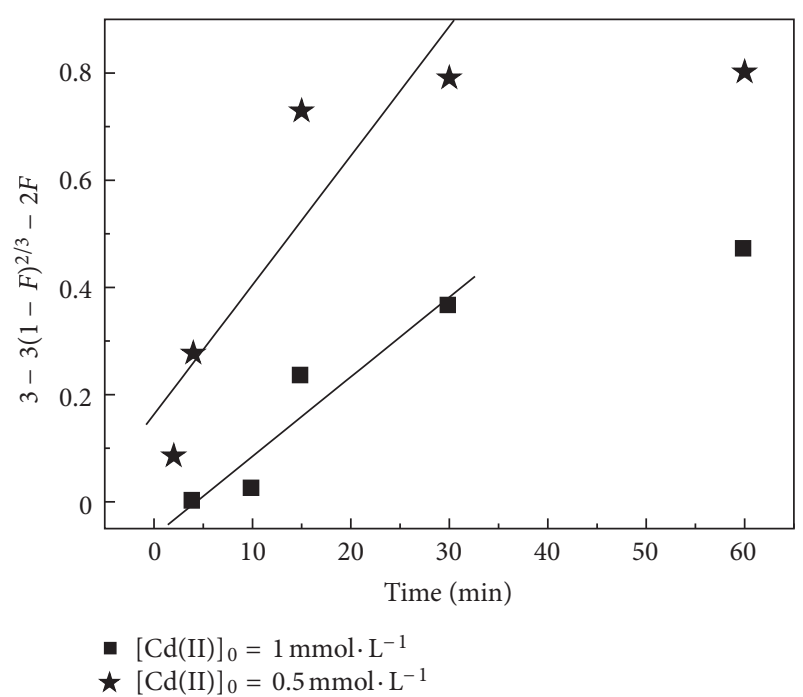

Figure 8: Plot of the moving boundary particle diffusion model for the Cd(II) adsorption on grafted resin, $m=0.030 \mathrm{~g}, V=5 \mathrm{~mL}$, and initial $\mathrm{pH}=5.0$.

The graphical correlation in Figure 8 of (13) shows that the moving boundary particle diffusion model fits only the initial adsorption on the grafted resin. The linear regression analyses of (13) are also given in Table 3.

3.7. Effect of Electrolytes on Cd(II) Extraction. As the sulphates, chlorides, and acetate of alkali ions $\left(\mathrm{Na}^{+}\right)$frequently accompany cadmium ions in industrial solutions, it is worthwhile to know if they affect the extraction process efficiency. 


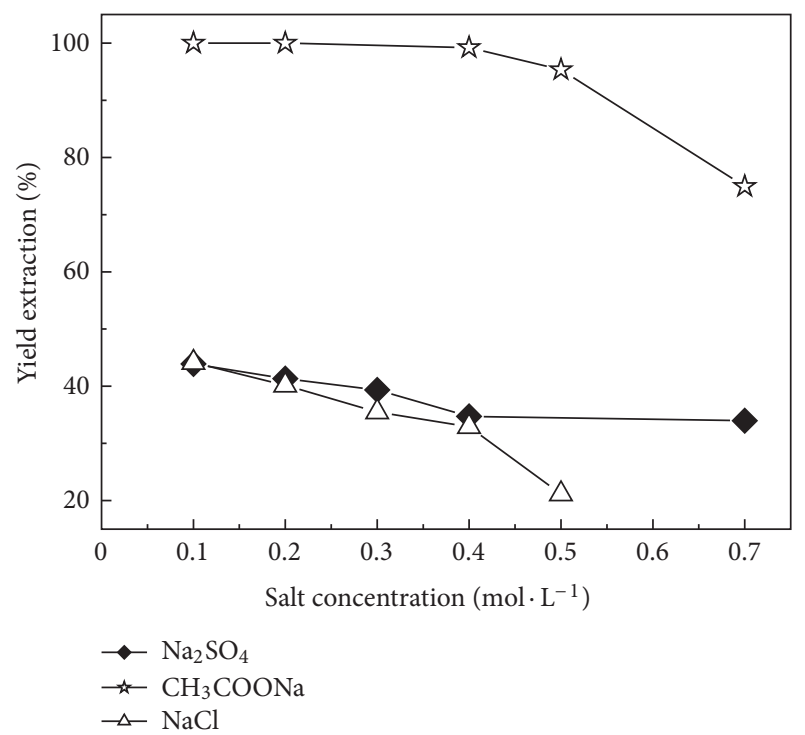

Figure 9: Effect of $\mathrm{Na}_{2} \mathrm{SO}_{4}, \mathrm{CH}_{3} \mathrm{COONa}$, and $\mathrm{NaCl}$ salts concentrations on the extraction of $\mathrm{Cd}(\mathrm{II})$ with grafted resin, $m=0.030 \mathrm{~g}$, $V=5 \mathrm{~mL}$, initial $\mathrm{pH}=5.0, C_{0}=1.0 \mathrm{mmol} / \mathrm{L}$, and equilibrium time $=180 \mathrm{~min}$.

The influence on the extraction of $\mathrm{Cd}(\mathrm{II})$ was studied at the varying concentrations of $\mathrm{NaCl}, \mathrm{Na}_{2} \mathrm{SO}_{4}$, and $\mathrm{CH}_{3} \mathrm{COONa}$, in aqueous solution, from 0.1 to $0.7 \mathrm{~mol} \cdot \mathrm{L}^{-1}$. The influence of the concentration of those salts is shown in Figure 9.

At $\mathrm{Na}_{2} \mathrm{SO}_{4}$ and $\mathrm{NaCl}$ concentrations between 0.1 and $0.7 \mathrm{~mol} \cdot \mathrm{L}^{-1}$ there is a negative trend on increasing electrolytes concentrations. The decrease in the extraction of $\mathrm{Cd}(\mathrm{II})$ may be due to the formation of more stable metal sulphate or chloride complexes, which were nonextractable by the grafted resin $[33,34]$.

The presence of $\mathrm{CH}_{3} \mathrm{COONa}$ does not become annoying until a concentration of $0.4 \mathrm{~mol} \cdot \mathrm{L}^{-1}$. At high concentration, it was found that the extraction yield drop from $100 \%$ to $75 \%$ when the acetate concentration increases from $0.4 \mathrm{~mol} \cdot \mathrm{L}^{-1}$ to $0.7 \mathrm{~mol} \cdot \mathrm{L}^{-1}$. This effect is attributed to a competition between $\mathrm{Na}^{+}$cations of added salt and $\mathrm{Cd}(\mathrm{II})$ in the formation of bonds with the active sites of the resin [34].

3.8. Effect of Temperature on Sorption. Temperature has two major effects on the sorption process. Increasing the temperature is known to increase the rate of the diffusion of the sorbate molecule across the external boundary layer and in the internal pores of the sorbent particle, owing to a decrease in the velocity of the solution. In addition, changing the temperature will change the equilibrium capacity of the sorbent for the particle sorbate. The influence of temperature variation was examined on the sorption of $\mathrm{Cd}(\mathrm{II})$ of fixed concentration $1.0 \mathrm{mmol} \mathrm{L}^{-1}$ onto grafted resin using $180 \mathrm{~min}$ of equilibration time and sorbent to aqueous phase ratio of $0.030 \mathrm{~g}$ : $5 \mathrm{~mL}$ from $293 \mathrm{~K}$ to $333 \mathrm{~K}$.

Experimental results (yield extraction) concerning the effect of temperature on the Cd(II) sorption are shown in Figure 10. An increase in temperature results is an increase

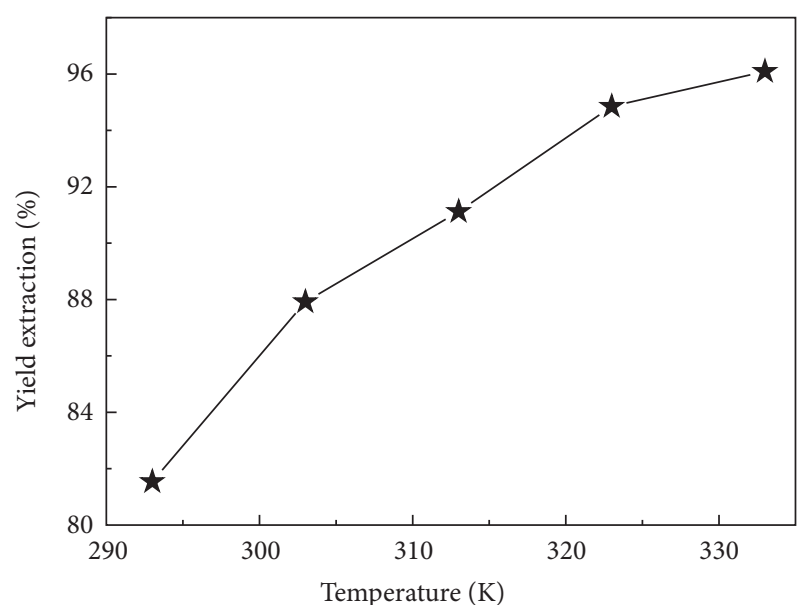

FIGURE 10: Effect of temperature on the yield extraction of Cd(II) by the functionalized resin. $C_{0}=1.0 \mathrm{mmol} \cdot \mathrm{L}^{-1}, m=0.030 \mathrm{~g}, V=5 \mathrm{~mL}$, initial $\mathrm{pH}=5.0$, and equilibrium time $=180 \mathrm{~min}$.

in metal ion sorption. There is about $15 \%$ increase in the yield sorption of $\mathrm{Cd}(\mathrm{II})$ sorbed on grafted resin when the temperature is raised from 293 to $333 \mathrm{~K}$. Better sorption at higher temperatures may be either due to acceleration of some originally slow sorption steps or due to the enhanced mobility of Cd(II) ions from the solution to the functionalized resin surface.

3.9. Thermodynamic Parameters. In environmental engineering practice, both energy and entropy factors must be considered in order to determine which process will occur spontaneously. The Gibbs free energy change, $\Delta G_{0}$, is the fundamental criterion of spontaneity [35].

The apparent thermodynamic parameters $\Delta H$ and $\Delta S$ for the sorption process were calculated from the slopes and intercepts of the linear variation of $\ln K_{d}$ versus $1 / T$ in Figure 11 by:

$$
\operatorname{Ln} K_{d}=\frac{\Delta S}{R}-\frac{\Delta H}{R T}
$$

where $R$ is the gas constant, $8.314 \mathrm{~J} \cdot \mathrm{mol}^{-1} \cdot \mathrm{K}^{-1}$ and $T$ is the absolute temperature in Kelvin. The free energy $(\Delta G)$ for the sorption was calculated by

$$
\Delta G=\Delta H-T \Delta S .
$$

Further, the thermodynamic equilibrium constant, $K_{d}$ in $\mathrm{mL} \cdot \mathrm{g}^{-1}(16)$, obtained from the distribution constant was used to compute the apparent thermodynamic parameters

$$
K_{d}=\frac{\left(C_{0}-C_{e}\right) V}{C_{e} m} .
$$

The calculated apparent thermodynamic parameters for sorption of Cd(II) onto functionalized resin are summarized in Table 4.

In the present work, the Gibbs energy decrease in each case was responsible for imparting stability to the cadmium 
TABLE 4: Thermodynamics parameters for sorption process of Cd(II) on functionalized resin.

\begin{tabular}{lccccr}
\hline$\Delta \mathrm{H},\left(\mathrm{kJ} \cdot \mathrm{mol}^{-1}\right)$ & $\Delta \mathrm{S},\left(\mathrm{J} \cdot \mathrm{mol}^{-1} \cdot \mathrm{K}^{-1}\right)$ & \multicolumn{5}{c}{$\Delta \mathrm{G},\left(\mathrm{kJ} \cdot \mathrm{mol}^{-1}\right)$} \\
\hline- & - & $293 \mathrm{~K}$ & $303 \mathrm{~K}$ & $313 \mathrm{~K}$ & $323 \mathrm{~K}$ \\
+35.53 & +133.34 & -3.57 & -4.90 & -6.24 & -7.57 \\
\hline
\end{tabular}

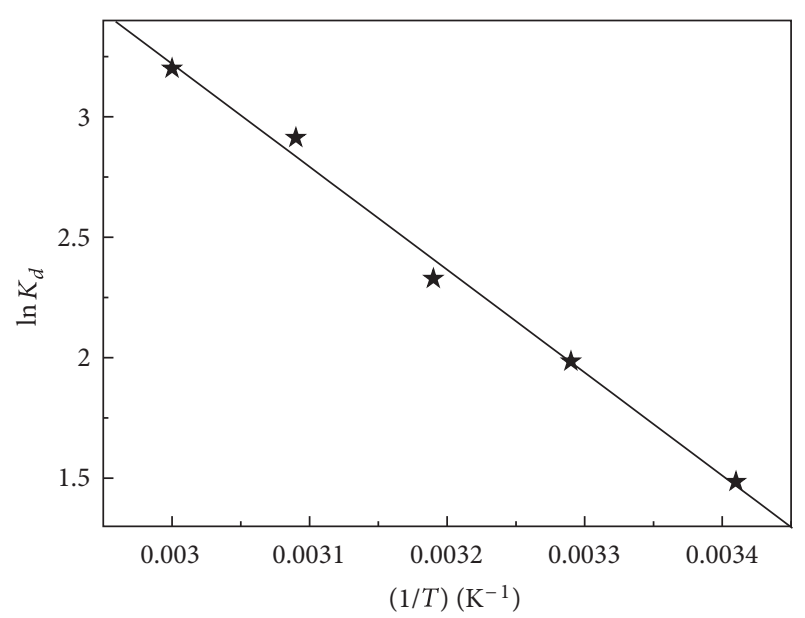

Figure 11: Variation of $\log K_{d}$ with $1 / T$ for the sorption of cadmium(II) onto the grafted resin, $m=0.030 \mathrm{~g},[\mathrm{Cd}(\mathrm{II})]_{0}=$ $1.0 \mathrm{mmol} \cdot \mathrm{L}^{-1}, V=5 \mathrm{~mL}$, initial $\mathrm{pH}=5.0$, and contact time $=$ $180 \mathrm{~min}$.

ions-functionalized resin sorption complexes. The negative values of $\Delta G$ are due to the fact that the sorption process is spontaneous with high affinity of $\mathrm{Cd}(\mathrm{II})$ ions to the derivative of phosphonic acids. However, the negative values of $\Delta G$ decrease indicating that the spontaneous nature of the sorption of metal ions is inversely proportional to the temperature; higher temperature favours the sorption process. The positive value of $\Delta H$ confirms the endothermic nature of the sorption process. Hence, by increasing temperature, the degree of sorption/exchange will increase. Increased temperature will cause a rupturing of the hydration zone formed around Cd(II) in mother liquid to a great extent and direct interaction of metal ions with functional group of resin (decreasing in hydrated diameter), increasing diffusion force by supplying partial ion-exchange activation energy, increasing diffusion into the inner sections of the grafted resin, and subsequently an increase in the degree of sorption/exchange. The positive value of $\Delta S$ reflected the affinity of the sorbent for Cd(II) ions and confirms the increased randomness at the solid-solution interface during sorption [36].

3.10. Elution Studies. Adsorption and elution processes depend on the solution $\mathrm{pH}$. Therefore, elution is possible by controlling the $\mathrm{pH} /$ acid concentration of the solution. Elution of Cd(II) from loaded grafted resin was carried out using $\mathrm{HCl}$ solution at different concentrations $\left(0.0\right.$ to $\left.2.5 \mathrm{~mol} \cdot \mathrm{L}^{-1}\right)$. The contact time was maintained at $120 \mathrm{~min}$. The results in Figure 12 show that percentage elution increased with increasing acid concentration and a hydrochloric acid concentration of $1.0 \mathrm{~mol} \cdot \mathrm{L}^{-1}$ was found suitable to elute more

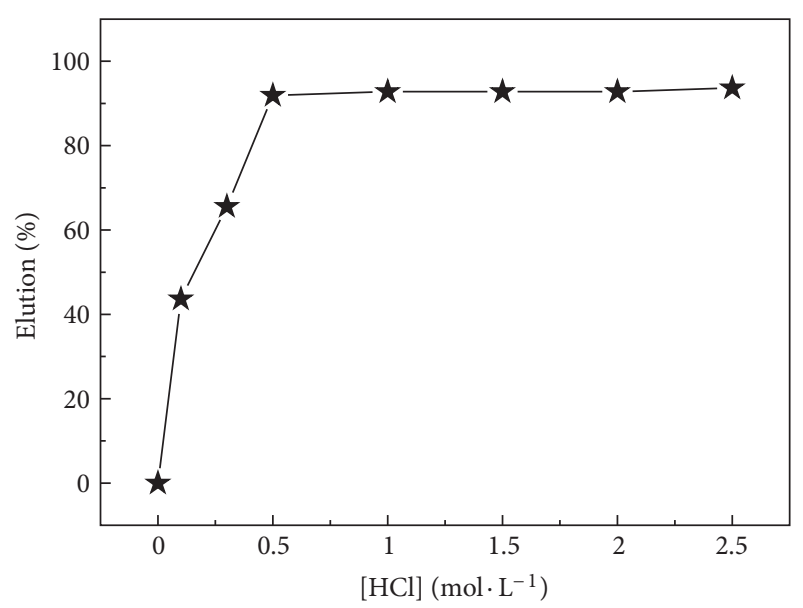

FIGURE 12: Effect of $\mathrm{HCl}$ concentration on the desorption of Cd(II) loaded on grafted resin. Loaded resin quantity: $0.030 \mathrm{~g}$, acid volume: $5 \mathrm{~mL}$, and time contact: $120 \mathrm{~min}$.

than $92 \%$ of the $\mathrm{Cd}(\mathrm{II})$ from the functionalized resin in one cycle.

\section{Conclusion}

The phosphonic acid grafted on polystyrene resin was synthesized using the Arbuzov reaction and used as a support material for $\mathrm{Cd}$ (II) sorption, in batch process. The extraction efficiency was determined as a function of various parameters such as time, $\mathrm{pH}$, cadmium concentration, and electrolytes effect. The experimental capacity obtained is $37.9 \mathrm{mg} \cdot \mathrm{g}^{-1}$. The kinetics of Cd(II) adsorption on functionalyzed resin follows the Pseudo second-order rate. The equilibrium isotherm for sorption of the investigated metal ions has been modelled successfully using the Langmuir isotherm. The Cd(II) uptake is best explained by a particle diffusion controlled process, whereas the moving boundary model only fits the initial adsorption on the phosphonic resin. Various thermodynamic parameters, such as $\Delta G, \Delta H$, and $\Delta S$, were calculated from the data. The thermodynamics of $\mathrm{Cd}$ (II) ions/functionalized resin system indicate a spontaneous and endothermic nature of the process.

More than $92 \%$ of loaded Cd(II) on the grafted resin can be eluted with $\mathrm{HCl} 1.0 \mathrm{~mol} \cdot \mathrm{L}^{-1}$ after 120 minutes of shaking in one cycle.

The results presented in this work reveal that polystyrene resin functionalized with phosphonic group is feasible for the removal of cadmium cations from wastewater. 


\section{Acknowledgments}

The authors gratefully acknowledge the Rohm and Haas Company for their generous gift of chloromethyl polystyrene and the Tassili Program no. 10 MDU799 for their financial support.

\section{References}

[1] B. Messner and D. Bernhard, "Cadmium and cardiovascular diseases: cell biology, pathophysiology, and epidemiological relevance," BioMetals, vol. 23, no. 5, pp. 811-822, 2010.

[2] C. - Gilmour and G. Riedel, "Biogeochemistry of trace metals and metalloids," in EncyclopEdia of Inland Waters, G. E. Likens, Ed., pp. 7-15, Elsevier, Amsterdam, The Netherlands, 2009.

[3] J. Pandey and U. Pandey, "Microbial processes at the land-water interface, and cross-domain causal relationships, as influenced by atmospheric deposition of pollutants in three freshwater lakes in India," Lakes and Reservoirs, vol. 14, no. 1, pp. 71-84, 2009.

[4] V. M. Fthenakis, "Life cycle impact analysis of cadmium in CdTe PV production," Renewable and Sustainable Energy Reviews, vol. 8, no. 4, pp. 303-334, 2004.

[5] W. B. Gurnule and D. B. Patle, "Metal ion binding properties of a copolymer resin: synthesis, characterization, and its applications," Polymer Bulletin, vol. 66, no. 6, pp. 803-820, 2011.

[6] A. Corami, S. Mignardi, and V. Ferrini, "Cadmium removal from single- and multi-metal $(\mathrm{Cd}+\mathrm{Pb}+\mathrm{Zn}+\mathrm{Cu})$ solutions by sorption on hydroxyapatite," Journal of Colloid and Interface Science, vol. 317, no. 2, pp. 402-408, 2008.

[7] A. Gaikwad, "The transport of metal ions through fiber supported solid membranes in mixed solvents," Fibers and Polymers, vol. 12, no. 1, pp. 21-28, 2011.

[8] O. Abderrahim, M. A. Didi, B. Moreau, and D. Villemin, "A new sorbent for selective separation of metal: polyethylenimine methylenephosphonic acid," Solvent Extraction and Ion Exchange, vol. 24, no. 6, pp. 943-955, 2006.

[9] K. S. - Rao, M. Mohapatra, S. Anand, and P. Venkateswarlu, "Review on cadmium removal from aqueous solutions," International Journal of Engineering, Science and Technology, vol. 2, no. 7, pp. 81-103, 2010.

[10] D. Villemin, B. Moreau, M. Kaid, and M. A. Didi, "Rapid one-pot synthesis of alkane- $\alpha \omega$, diylbisphosphonic acids from dihalogenoalkanes under microwave irradiation," Phosphorus, Sulfur and Silicon and the Related Elements, vol. 185, no. 8, pp. 1583-1586, 2010.

[11] D. Meziane, J. Hardouin, A. Elias, E. Guénin, and M. Lecouvey, "Microwave michaelis-becker synthesis of diethyl phosphonates, tetraethyl diphosphonates, and their total or partial dealkylation," Heteroatom Chemistry, vol. 20, no. 6, pp. 369-377, 2009.

[12] A. N. Pustam and S. D. Alexandratos, "Engineering selectivity into polymer-supported reagents for transition metal ion complex formation," Reactive and Functional Polymers, vol. 70, no. 8, pp. 545-554, 2010.

[13] A. Popa, C. M. Davidescu, P. Negrea, G. Ilia, A. Katsaros, and K. D. Demadis, "Synthesis and characterization of phosphonate ester/phosphonic acid grafted styrene-divinylbenzene copolymer microbeads and their utility in adsorption of divalent metal ions in aqueous solutions," Industrial and Engineering Chemistry Research, vol. 47, no. 6, pp. 2010-2017, 2008.
[14] M. C. Zenobi, C. V. Luengo, M. J. Avena, and E. H. Rueda, "An ATR-FTIR study of different phosphonic acids in aqueous solution," Spectrochimica Acta-Part A, vol. 70, no. 2, pp. 270-276, 2008.

[15] E. Y. Hashem, "Spectrophotometric studies on the simultaneous determination of cadmium and mercury with 4-(2pyridylazo)-resorcinol," Spectrochimica Acta-Part A, vol. 58, no. 7, pp. 1401-1410, 2002.

[16] M. F. Elkady, M. M. Mahmoud, and H. M. Abd-El-Rahman, "Kinetic approach for cadmium sorption using microwave synthesized nano-hydroxyapatite," Journal of Non-Crystalline Solids, vol. 357, no. 3, pp. 1118-1129, 2011.

[17] M. S. Dzul Erosa, T. I. Saucedo Medina, R. Navarro Mendoza, M. Avila Rodriguez, and E. Guibal, "Cadmium sorption on chitosan sorbents: kinetic and equilibrium studies," Hydrometallurgy, vol. 61, no. 3, pp. 157-167, 2001.

[18] V. Arámbula-Villazana, M. Solache-Ríos, and M. T. Olguín, "Sorption of cadmium from aqueous solutions at different temperatures by Mexican HEU-type zeolite rich tuff," Journal of Inclusion Phenomena and Macrocyclic Chemistry, vol. 55, no. 3-4, pp. 229-236, 2006.

[19] R. Cortés-Martínez, V. Martínez-Miranda, M. Solache-Ríos, and I. García-Sosa, "Evaluation of natural and surfactantmodified zeolites in the removal of cadmium from aqaeous solutions," Separation Science and Technology, vol. 39, no. 11, pp. 2711-2730, 2004.

[20] J. I. Dávila-Rangel, M. Solache-Ríos, and V. E. Badillo-Almaraz, "Comparison of three Mexican aluminosilicates for the sorption of cadmium," Journal of Radioanalytical and Nuclear Chemistry, vol. 267, no. 1, pp. 139-145, 2005.

[21] Z. N. Shu, C. H. Xiong, and X. Wang, "Adsorption behavior and mechanism of amino methylene phosphonic acid resin for Ag(I)," Transactions of Nonferrous Metals Society of China, vol. 16, no. 3, pp. 700-704, 2006.

[22] W. S. Eun and R. M. Rowell, "Cadmium ion sorption onto lignocellulosic biosorbent modified by sulfonation: the origin of sorption capacity improvement," Chemosphere, vol. 60, no. 8, pp. 1054-1061, 2005.

[23] H. Harmita, K. G. Karthikeyan, and X. Pan, "Copper and cadmium sorption onto kraft and organosolv lignins," Bioresource Technology, vol. 100, no. 24, pp. 6183-6191, 2009.

[24] S. Izanloo and H. Nasseri, "Cadmium removal from aqueous solutions by ground pine cone," Iranian Journal of Environmental Health Science \& Engineering, vol. 2, no. 1, pp. 33-42, 2005.

[25] O. Abderrahim, N. Ferrah, M. A. Didi, and D. Villemin, "A new sorbent for europium nitrate extraction: phosphonic acid grafted on polystyrene resin," Journal of Radioanalytical and Nuclear Chemistry, vol. 209, pp. 267-275, 2011.

[26] N. Ferrah, O. Abderrahim, M. A. Didi, and D. Villemin, "Sorption efficiency of a new sorbent towards uranyl: phosphonic acid grafted Merrifield resin," Journal of Radioanalytical and Nuclear Chemistry, vol. 289, no. 3, pp. 721-730, 2011.

[27] J. Arichi, G. Goetz-Grandmont, and J. P. Brunette, "Solvent extraction of europium(III) from nitrate medium with 4-acylisoxazol-5-ones and 4-acyl-5-hydroxy-pyrazoles. Effect of salts and diluents," Hydrometallurgy, vol. 82, no. 1-2, pp. 100-109, 2006.

[28] Q. Hu, Y. Meng, T. Sun et al., "Kinetics and equilibrium adsorption studies of dimethylamine (DMA) onto ion-exchange resin," Journal of Hazardous Materials, vol. 185, no. 2-3, pp. 677-681, 2011. 
[29] H. K. Boparai, M. Joseph, and D. M. O'Carroll, "Kinetics and thermodynamics of cadmium ion removal by adsorption onto nano zerovalent iron particles," Journal of Hazardous Materials, vol. 186, no. 1, pp. 458-465, 2011.

[30] S. Suganthi and K. Srinivasan, "Phosphorylated tamarind nut carbon for the removal of cadmium ions from aqueous solutions," Indian Journal of Engineering and Materials Sciences, vol. 17, no. 5, pp. 382-388, 2010.

[31] D. C. K. Ko, J. F. Porter, and G. McKay, "Film-pore diffusion model for the fixed-bed sorption of copper and cadmium ions onto bone char," Water Research, vol. 35, no. 16, pp. 3876-3886, 2001.

[32] W. Guan, J. Pan, H. Ou et al., "Removal of strontium(II) ions by potassium tetratitanate whisker and sodium trititanate whisker from aqueous solution: equilibrium, kinetics and thermodynamics," Chemical Engineering Journal, vol. 167, no. 1, pp. 215-222, 2011.

[33] Y. Egozy, "Adsorption of cadmium and cobalt on montmorillonite as a function of solution composition," Clays and Clay Minerals, vol. 28, no. 4, pp. 311-318, 1980.

[34] I. Ghodbane, L. Nouri, O. Hamdaoui, and M. Chiha, "Kinetic and equilibrium study for the sorption of cadmium(II) ions from aqueous phase by eucalyptus bark," Journal of Hazardous Materials, vol. 152, no. 1, pp. 148-158, 2008.

[35] P. Senthil Kumar, K. Ramakrishnan, S. Dinesh Kirupha, and S. Sivanesan, "Thermodynamic and kinetic studies of cadmium adsorption from aqueous solution onto rice husk," Brazilian Journal of Chemical Engineering, vol. 27, no. 2, pp. 347-355, 2010.

[36] S. Mustafa, M. Waseem, A. Naeem, K. H. Shah, T. Ahmad, and S. Y. Hussain, "Selective sorption of cadmium by mixed oxides of iron and silicon," Chemical Engineering Journal, vol. 157, no. 1, pp. 18-24, 2010. 

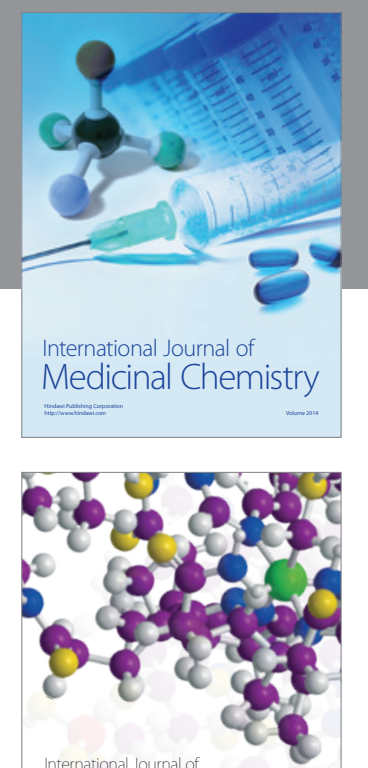

\section{Carbohydrate} Chemistry

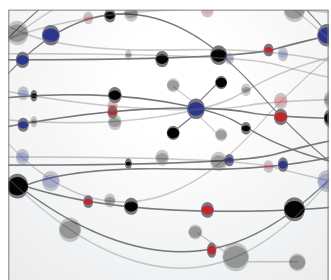

The Scientific World Journal
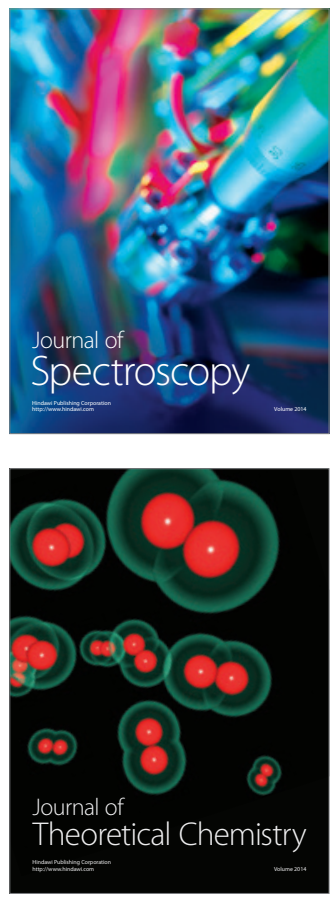
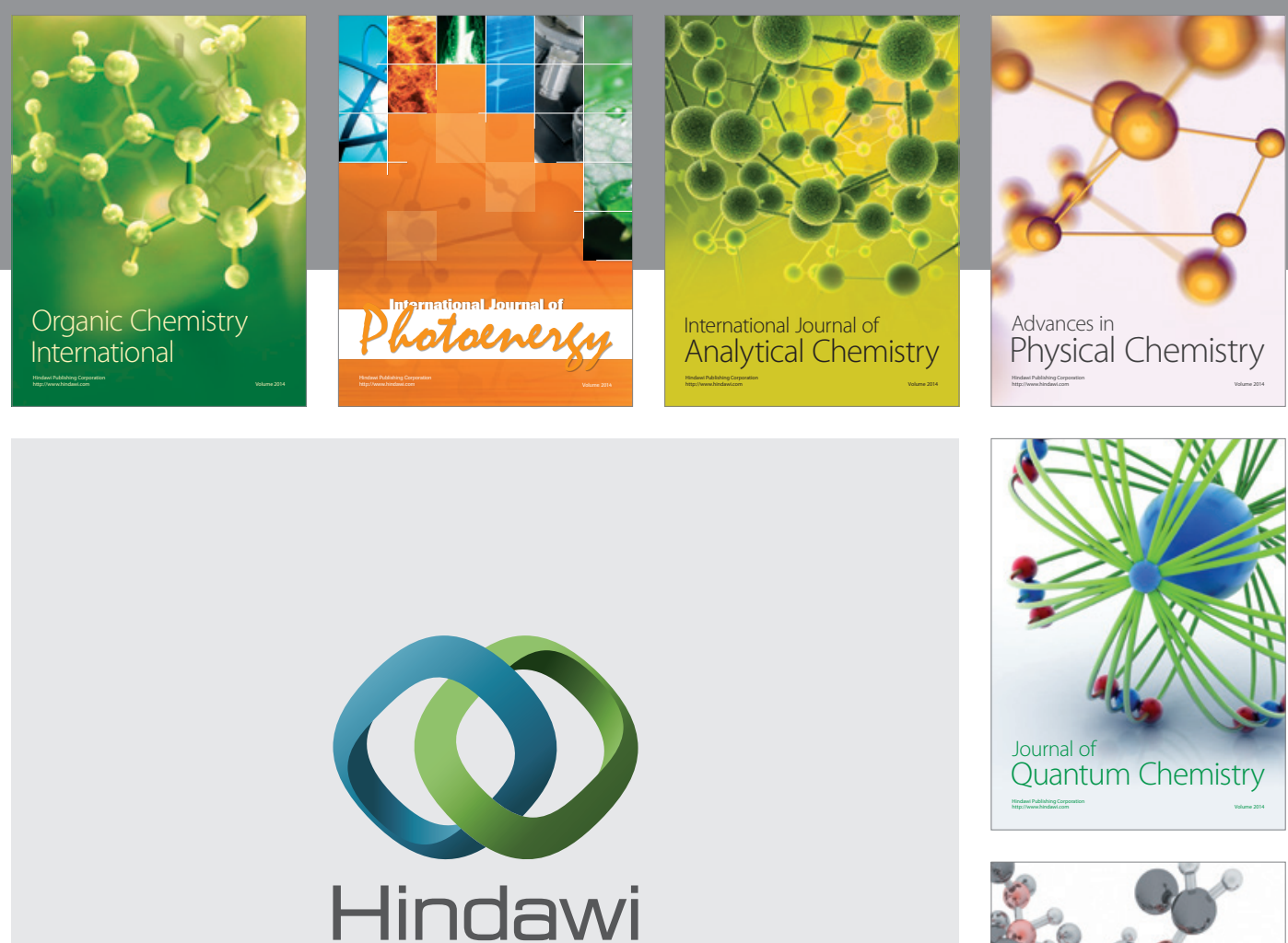

Submit your manuscripts at

http://www.hindawi.com

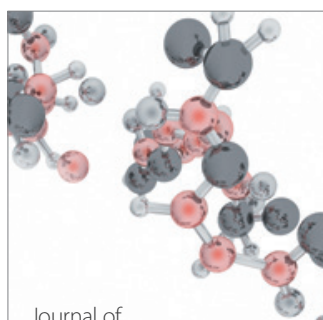

Analytical Methods

in Chemistry

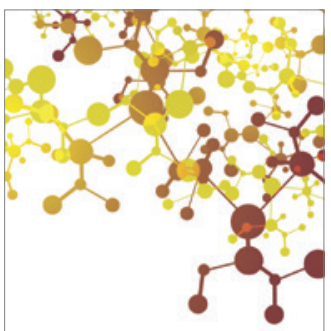

Journal of

Applied Chemistry

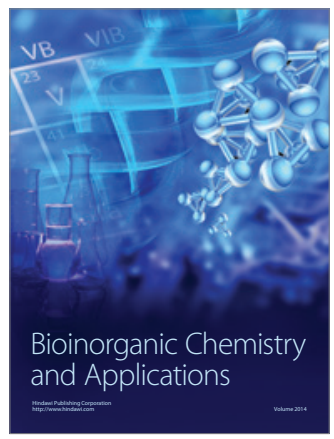

Inorganic Chemistry
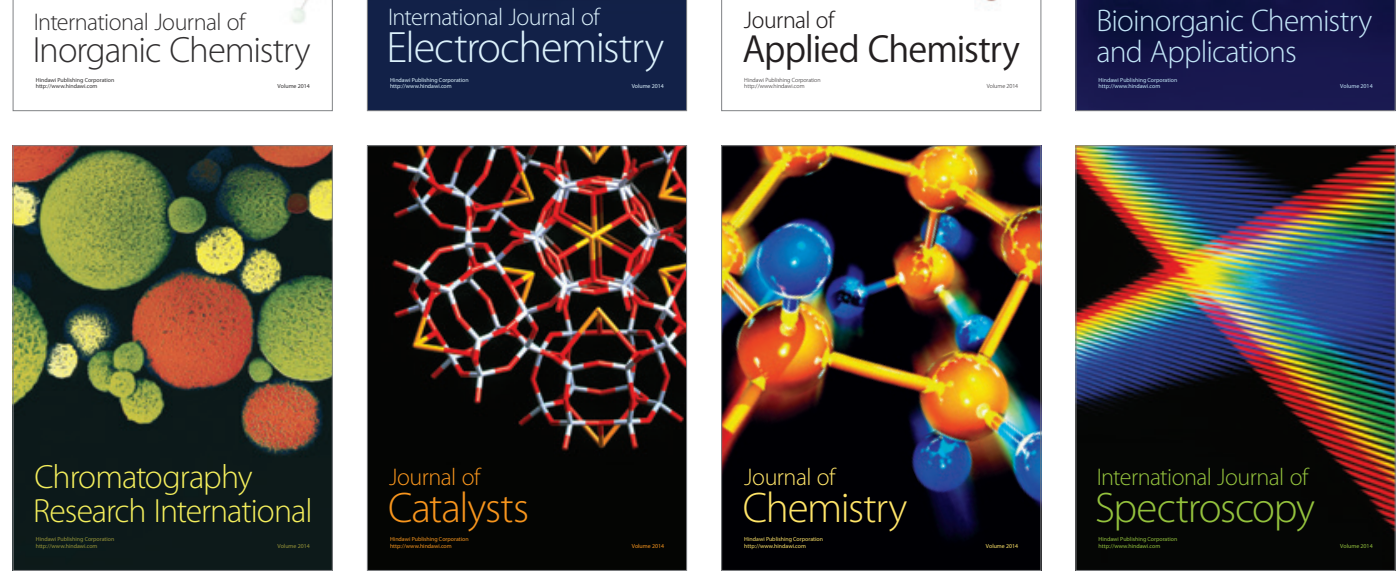